\title{
Direct, inflammation-mediated and blood-pressure-mediated effects of total and abdominal adiposity on diastolic function: EPIPorto study
}

\author{
Ricardo Fontes-Carvalho a,b,c,*, Alexandra Gonçalves ${ }^{\mathrm{c}, \mathrm{d}}$, Milton Severo a,e, Patrícia Lourenço ${ }^{\mathrm{f}}$, \\ Francisco Rocha Gonçalves ${ }^{\mathrm{g}}$, Paulo Bettencourt ${ }^{\mathrm{f}, \mathrm{g}}$, Adelino Leite-Moreira ${ }^{\mathrm{c}, \mathrm{h}}$, Ana Azevedo ${ }^{\mathrm{a}, \mathrm{e}}$ \\ a EPIUnit - Institute of Public Health, University of Porto (ISPUP), Porto, Portugal \\ b Cardiology Department, Gaia Hospital Center, Gaia, Portugal \\ c Department of Physiology and Cardiothoracic Surgery, Faculty of Medicine, University of Porto, Porto, Portugal \\ d Cardiovascular Division, Brigham and Women's Hospital, Boston, MA, USA \\ e Department of Clinical Epidemiology, Predictive Medicine and Public Health, Faculty of Medicine, University of Porto, Porto, Portugal \\ ${ }^{\mathrm{f}}$ Heart Failure Clinic, Department of Internal Medicine, Centro Hospitalar São João, Porto, Portugal \\ ${ }^{g}$ Department of Medicine, Faculty of Medicine, University of Porto, Porto, Portugal \\ ${ }^{\text {h }}$ Department of Cardiothoracic Surgery, Centro Hospitalar São João, Porto, Portugal
}

\section{A R T I C L E I N F O}

\section{Article history:}

Received 11 August 2014

Received in revised form 11 January 2015

Accepted 30 April 2015

Available online 1 May 2015

\section{Keywords:}

Diastole

Obesity

Waist circumference

Sex

\begin{abstract}
A B S T R A C T
Background: Obesity has been associated with subclinical diastolic dysfunction and increased risk of heart failure. Our aims were to evaluate the age- and sex-specific role of total and abdominal adiposity on diastolic function and to assess the direct and indirect pathophysiological mechanisms involved in this association. Methods and results: Within a population-based study (EPIPorto), a total of 1063 individuals aged $\geq 45$ years ( $62 \%$ female; $62.4 \pm 10.6$ years) were evaluated using echocardiography, anthropometrics, electrical bioimpedance and blood tests. Diastolic function was assessed with using EAE/ASE consensus criteria.

Worse diastolic function grades were associated with increased BMI, fat mass \% and waist-to-height ratio ( $\mathrm{p}$ for trend $<0.001$ ). The inverse association between adiposity and diastolic function was stronger in men and in the younger population. In multivariate analysis, waist-to-height ratio $\left(\right.$ per $\mathrm{cm} / \mathrm{cm}$ ) was associated with reduced $\mathrm{E}^{\prime}$ velocity (adjusted $\beta$ : $-14.4 ; 95 \% \mathrm{Cl}:-21.1$ to $-7.6 ; \mathrm{p}<0.001$ ) and increased $\mathrm{E} / \mathrm{E}^{\prime}$ ratio (adjusted $\beta$ : 9.7, 95\% CI: 5.4-10.0; $\mathrm{p}<0.001$ ), among men $<65$ years.

Both direct and indirect mechanisms were involved in the $\mathrm{E}^{\prime}$ velocity decrease by waist-to-height ratio in participants $<65$ years. The effect was mainly direct in men (81.3\%), while it was mostly indirect in women, through systolic blood pressure (50.8\%) and inflammation (15.1\%).

Conclusions: Adiposity, especially abdominal, was associated with worse diastolic function. This association was more important in men and in the younger population. The causal mechanisms involved were sex-specific, with mostly direct effects among men and blood-pressure-mediated among women.
\end{abstract}

(c) 2015 Elsevier Ireland Ltd. All rights reserved.

\section{Introduction}

In heart failure progression, alterations in myocardial structure and function appear before the onset of symptoms, a process known as myocardial remodeling [1]. Recent heart failure guidelines give special emphasis to the early detection of these asymptomatic changes on left ventricle (LV) systolic and diastolic functions and the identification of its main risk factors $[2,3]$.

Heart failure with preserved ejection fraction (HFpEF), accounts for approximately $50 \%$ of heart failure patients $[4,5]$ and its prevalence is increasing [4]. Several pathophysiological mechanisms are involved in

\footnotetext{
* Corresponding author at: Cardiology Department, Gaia Hospital Center, Rua Conceicao Fernandes, 4434-502 Vila Nova Gaia, Portugal.

E-mail address: fontes.carvalho@gmail.com (R. Fontes-Carvalho).
}

HFpEF [6], but it is clear that diastolic dysfunction (caused by alterations in myocardial relaxation and/or increased left ventricle stiffness) is present in nearly all of these patients [7]. Therefore, current consensus guidelines recommend that evidence of abnormal LV diastolic function should be required for the diagnosis of HFpEF [3,8]. Population-based studies and registries have shown that patients with HFpEF are older, more frequently women, with a higher prevalence of hypertension, atrial fibrillation, diabetes and obesity [4].

Obesity has reached epidemic proportions worldwide and is now recognized as an independent risk factor for heart failure [9-11] and other cardiovascular diseases $[10,12]$. Recent studies have shown that increased body mass index can induce subclinical LV diastolic dysfunction (DD) [13], suggesting that DD can be one of the pathophysiological links between obesity and heart failure $[11,12]$. Obesity can induce DD by several potential mechanisms $[14,12]$. The effect can be direct by 
adipokine secretion $[15,16]$, by inducing a systemic pro-inflammatory state $[17,18]$ and changes in LV hemodynamics $[19,20]$, or indirect through its association with other cardiovascular risk factors, such as hypertension, insulin resistance and diabetes [10]. The role of central versus total adiposity on diastolic function is less well characterized. Abdominal obesity is associated with excess visceral fat, which is a metabolically more active fat, and probably a more important determinant of cardiac function and cardiovascular disease than total adiposity [21]. In addition, it is known that the distribution of fat is different between men and women and that age also induces important changes in the quantity of fat and its anatomic distribution.

In this study we aimed to evaluate: 1 ) the role of abdominal and total adiposity parameters in diastolic dysfunction; 2) the influence of sex and age on this association; and 3 ) the direct (adiposity mediated) and indirect (blood-pressure- and inflammation-mediated) mechanisms involved in the association between obesity and diastolic function.

\section{Methods}

\subsection{Study sample}

Participants were selected within the first follow-up of a cohort, representative at baseline of the adult population of Porto, Portugal - the EPIPorto cohort study. In 1999-2003, the cohort assembly was made by random-digit dialing, using households as the sampling frame, followed by random selection of one person aged 18 years or older in each household. Refusals were not substituted within the same household. The proportion of participation was 70\% [22]. At baseline, 2485 participants were recruited. Between October 2006 and July 2008, participants aged 45 years or over were eligible to a systematic evaluation of parameters of cardiac structure and function, which included a cardiovascular clinical history, physical examination, detailed anthropometric evaluation, collection of fasting blood sample and a transthoracic echocardiogram. Among 2048 cohort members in the eligible age range at this time, 134 (6.5\%) had died, 198 (9.7\%) refused to be re-evaluated and 580 (28.3\%) were lost to follow-up (unreachable by telephone or post). For the present analysis we excluded 73 patients with previous myocardial infarction, percutaneous or surgical revascularization, prior cardiac surgery or significant (moderate to severe) valvular heart disease. Written informed consent was obtained from all the individuals and the local ethics committee approved the study.

\subsection{Clinical variable definitions}

Hypertension was defined as systolic blood pressure $\geq 140 \mathrm{~mm} \mathrm{Hg}$ or diastolic blood pressure $\geq 90 \mathrm{~mm} \mathrm{Hg}$ at the time of the visit (mean of 2 readings) or use of antihypertensive medication. Diabetes was defined as fasting blood glucose $\geq 126 \mathrm{mg} / \mathrm{dL}$ or the patient's self-reported history of diabetes or use of diabetes medications. Hypercholesterolemia was defined as total serum cholesterol $\geq 220 \mathrm{mg} / \mathrm{dL}$ or the use of lipidlowering drug treatment.

\subsection{Anthropometric evaluation}

Measurements included height, weight, waist circumference, and hip circumference. Body mass index (BMI) (weight $/$ height ${ }^{2}$ in $\mathrm{kg} / \mathrm{m}^{2}$ ) was calculated for each subject. Waist circumference was measured at the midpoint between the iliac crest and the lower rib margins measured in the midaxillary line. Overweight was defined as BMI $\geq 25$ and below $30 \mathrm{~kg} / \mathrm{m}^{2}$, and obesity as BMI $\geq 30 \mathrm{~kg} / \mathrm{m}^{2}$. Hip-to-height and waist-to-height ratios were calculated as the ratio between hip circumference $(\mathrm{cm})$ or waist circumference $(\mathrm{cm})$, respectively, and height $(\mathrm{cm})$. Body composition was assessed by bioelectrical impedance analysis (Tanita Corp, Arlington Heights, IL) to determine body fat percentage (\%).

\subsection{Analytical data}

A fasting venous blood sample was obtained in the morning for measurement of glucose, total cholesterol, LDL, HDL, triglycerides and highsensitivity C-reactive protein (by immunonephelometry).

\subsection{Echocardiography data}

All echocardiography studies were acquired by one of four cardiologists, using the same equipment (Hewlett-Packard Sonos 5500). Images were stored on videotape for posterior offline analysis by two experienced cardiologists, blinded to clinical data.

Cardiac chamber dimensions, volumes and left ventricular mass were measured according to current recommendations [23], and indexed to body surface area. Diastolic function was assessed according to the recent consensus guidelines on diastolic function evaluation [24] measuring mitral inflow velocities (E-wave, A wave, E/A ratio) and E-wave deceleration time (DT) and isovolumetric relaxation time (IVRT) using pulsed-wave (PW) Doppler in the apical four-chamber view. Velocities were recorded at end-expiration and averaged over three consecutive cardiac cycles. PW tissue-Doppler velocities were acquired at end expiration, in the apical four-chamber view, at the lateral side of the mitral annulus, measuring early diastolic $\left(E^{\prime}\right)$ and late diastolic $\left(A^{\prime}\right)$ velocities and estimating the $\mathrm{E} / \mathrm{E}^{\prime}$ ratio accordingly. Following the recommendations in the consensus document, patients were categorized by two independent cardiologists in DD grades: grade I (mild DD) if $\mathrm{E}^{\prime}$ lateral $<10 \mathrm{~cm} / \mathrm{s}$ and $\mathrm{E} / \mathrm{A}<0.8$, $\mathrm{DT}>200 \mathrm{~ms}, \mathrm{E} / \mathrm{E} \leq 8$; grade II (moderate DD) if $\mathrm{E}^{\prime}$ lateral $<10 \mathrm{~cm} / \mathrm{s}$ and $\mathrm{E} / \mathrm{A}$ between 0.8 and 1.5 , DT 160-200 ms, E/E' 9-12; and grade III (severe $\mathrm{DD}$ ), if $\mathrm{E}^{\prime}$ lateral $<10 \mathrm{~cm} / \mathrm{s}$ and $\mathrm{E} / \mathrm{A} \geq 2, \mathrm{DT}<160, \mathrm{E} / \mathrm{E}^{\prime} \geq 13$. In case of discordance, each case was discussed individually. Systolic function was evaluated by ejection fraction calculation using the modified biplane Simpson's rule.

\subsection{Statistical analysis}

Statistical analyses were performed using SPSS statistics 20 (IBM Corp, Armonk, NY). All p values are 2-tailed and a significance level of $5 \%$ was used. Data are expressed as mean and standard deviation for quantitative variables or number ( $\mathrm{n}$ ) and percentage (\%) for categorical variables. Because C-reactive protein was not normally distributed, a logarithmic transformation was performed, achieving a normal distribution of this variable.

The determinants of $\mathrm{E}^{\prime}$ velocity and $\mathrm{E} / \mathrm{E}^{\prime}$ ratio were explored using linear regression analysis. To analyze the determinants of diastolic dysfunction, logistic regression analysis was performed. The association between adiposity and all diastolic function parameters was analyzed stratifying by sex and age (cut-off: 65 years) and adjusting for age and systolic blood pressure (continuous variables). Adjustment for age (continuous) within age strata intended to control for residual confounding.

Path analysis is an extension of regression analysis which allows for the simultaneous estimation of the interrelations between variables in a set [25]. This technique is being increasingly used to decompose and compare the magnitudes of effects between variables with complex interrelations or to test the plausibility of mediation effects. We conducted path analysis assuming the possible causal model depicted in Fig. 1. Models were fitted with Mplus software (Muthén and Muthén, Los Angeles, CA); 95\% confidence intervals were calculated by bootstrapping; and goodness of fit was evaluated using the comparative fit index (CFI). Models were considered to have good fit if CFI was higher than 0.90 .

\section{Results}

The final analysis included 1063 participants with a mean age of $62.4 \pm 10.6$ years and $62.0 \%$ were women. Table 1 shows the clinical, 


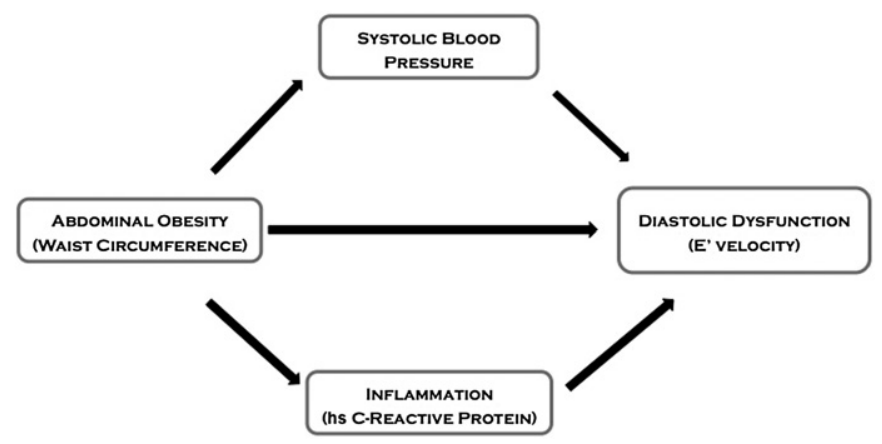

Fig. 1. Hypothesized causal mechanisms linking abdominal adiposity and diastolic dysfunction.

anthropometric, analytical and echocardiographic characteristics of the study sample, by sex. There was a high prevalence of cardiovascular risk factors, especially hypertension and dyslipidemia.

The total prevalence of diastolic dysfunction was $23.1 \%$ : $14.2 \%$ had mild diastolic dysfunction and $8.9 \%$ had moderate or severe diastolic dysfunction, as shown in Table 2. No significant differences were

Table 1

Characteristics of the study sample, by sex.

\begin{tabular}{|c|c|c|}
\hline & Women $(\mathrm{n}=659)$ & Men $(n=404)$ \\
\hline \multicolumn{3}{|l|}{ Clinical data } \\
\hline Age, years & $62.0 \pm 10.3$ & $63.1 \pm 11.1$ \\
\hline \multicolumn{3}{|l|}{ Cardiovascular risk factors } \\
\hline Hypertension (\%) & $465(70.6 \%)$ & $293(72.5 \%)$ \\
\hline Diabetes (\%) & $75(11.4 \%)$ & $51(12.6 \%)$ \\
\hline Dyslipidemia (\%) & $379(57.5 \%)$ & $204(50.5 \%)$ \\
\hline Obesity (\%) & 207 (31.4\%) & $55(13.6 \%)$ \\
\hline Systolic blood pressure, mm Hg & $134.9 \pm 22.0$ & $134.9 \pm 18.0$ \\
\hline Diastolic blood pressure, $\mathrm{mm} \mathrm{Hg}$ & $81.4 \pm 11.0$ & $82.0 \pm 10.3$ \\
\hline \multicolumn{3}{|l|}{ Adiposity parameters } \\
\hline BMI, $\mathrm{kg} / \mathrm{m}^{2}$ & $28.2 \pm 5.1$ & $26.5 \pm 3.7$ \\
\hline Waist circumference/height, $\mathrm{cm} / \mathrm{m}$ & $0.89 \pm 0.08$ & $0.57 \pm 0.06$ \\
\hline Hip circumference/height, cm/m & $0.67 \pm 0.07$ & $0.59 \pm 0.04$ \\
\hline Waist-to-hip ratio & $0.89 \pm 0.07$ & $0.97 \pm 0.06$ \\
\hline Fat mass, $\%$ & $35.5 \pm 6.9$ & $24.3 \pm 5.5$ \\
\hline \multicolumn{3}{|l|}{ Analytical data } \\
\hline Total cholesterol, mg/dL & $220.1 \pm 51.7$ & $214.1 \pm 56.7$ \\
\hline $\mathrm{HDL}, \mathrm{mg} / \mathrm{dL}$ & $61.5 \pm 43.1$ & $56.8 \pm 48.6$ \\
\hline $\mathrm{LDL}, \mathrm{mg} / \mathrm{dL}$ & $134.0 \pm 51.1$ & $131.0 \pm 57.1$ \\
\hline Triglycerides, mg/dL & $151.1 \pm 43.8$ & $167.9 \pm 50.3$ \\
\hline Glucose, $\mathrm{mg} / \mathrm{dL}$ & $102.0 \pm 43.1$ & $108.6 \pm 53.0$ \\
\hline Log hs-CRP, mg/dL & $-0.68 \pm 0.46$ & $-0.77 \pm 0.50$ \\
\hline \multicolumn{3}{|l|}{ Echocardiography } \\
\hline Septum, mm & $8.4 \pm 1.4$ & $9.1 \pm 1.4$ \\
\hline Posterior wall, mm & $7.7 \pm 1.2$ & $8.4 \pm 1.3$ \\
\hline LV mass index, $\mathrm{g} / \mathrm{m}^{2}$ & $86.7 \pm 18.1$ & $86.8 \pm 24.2$ \\
\hline Left atrium volume index, $\mathrm{mL} / \mathrm{m}^{2}$ & $29.7 \pm 10.9$ & $29.7 \pm 12.4$ \\
\hline LV end-diastolic volume, $\mathrm{mL} / \mathrm{m}^{2}$ & $63.6 \pm 15.8$ & $71.6 \pm 18.7$ \\
\hline LV end-systolic volume, $\mathrm{mL} / \mathrm{m}^{2}$ & $25.6 \pm 9.1$ & $25.6 \pm 9.1$ \\
\hline Ejection fraction, $\%$ & $61.1 \pm 6.3$ & $58.5 \pm 7.7$ \\
\hline E wave, $\mathrm{cm} / \mathrm{s}$ & $73.7 \pm 15.8$ & $67.9 \pm 15.2$ \\
\hline A wave, $\mathrm{cm} / \mathrm{s}$ & $81.2 \pm 20.2$ & $74.2 \pm 18.6$ \\
\hline $\mathrm{E} / \mathrm{A}$ ratio & $0.96 \pm 0.32$ & $0.96 \pm 0.33$ \\
\hline Deceleration time, ms & $234.8 \pm 52.7$ & $242.9 \pm 63.3$ \\
\hline IVRT, ms & $91.5 \pm 16.1$ & $92.6 \pm 16.1$ \\
\hline $\mathrm{E}^{\prime}$ velocity, $\mathrm{cm} / \mathrm{s}$ & $10.4 \pm 3.2$ & $10.5 \pm 3.3$ \\
\hline $\mathrm{E} / \mathrm{E}^{\prime}$ ratio & $7.7 \pm 2.8$ & $7.0 \pm 2.6$ \\
\hline \multicolumn{3}{|l|}{ Diastolic dysfunction (DD) grade } \\
\hline Normal diastolic function, $\mathrm{n}(\%)$ & $482(73.1 \%)$ & $310(76.7 \%)$ \\
\hline Mild DD, n (\%) & $99(15.0 \%)$ & $52(12.9 \%)$ \\
\hline Moderate/severe DD, n (\%) & $63(9.6 \%)$ & $32(7.9 \%)$ \\
\hline
\end{tabular}

Data are presented as mean and standard deviation for continuous variables and count and percentage for categorical variables.

$\mathrm{BMI}$, body mass index; hs-CRP, high sensitivity $\mathrm{C}$ reactive protein; $\mathrm{DD}$, diastolic dysfunction; IVRT, isovolumetric relaxation time; LV, left ventricle. found in DD grades according to sex $(\mathrm{p}=0.20)$. In 25 patients $(2.4 \%)$ it was not possible to determine DD grade due to atrial fibrillation or fusion of the E/A mitral flow pattern. Patients with diastolic dysfunction were older, had increased systolic and diastolic blood pressure and higher levels of C-reactive protein. Left ventricle mass was higher in patients with diastolic dysfunction, which also showed decreased $\mathrm{E}^{\prime}$ velocities and increased $\mathrm{E} / \mathrm{E}^{\prime}$ ratio.

\subsection{Adiposity parameters and diastolic dysfunction grades}

Overall, overweight and obese participants had higher prevalence of diastolic dysfunction: $27.0 \%$ in the overweight, $26.3 \%$ in the obese and $14.7 \%$ in individuals with $\mathrm{BMI}<25 \mathrm{~kg} / \mathrm{m}^{2}$. In addition, as shown in Table 2, participants with diastolic dysfunction had a significant increase in BMI, fat mass percentage, waist circumference/height, hipcircumference/height and waist-to-hip ratio $(p<0.001)$. The association between diastolic function and adiposity parameters was different according to sex and age.

\subsection{Adiposity and diastolic dysfunction in women}

Overall, in women there was no significant relation between BMI and $\mathrm{E}^{\prime}$ velocity or $\mathrm{E} / \mathrm{E}^{\prime}$ ratio, after adjustment for age and systolic blood pressure, either below or above 65 years of age. However, in women younger than 65 years we observed a significant association between total fat mass percentage and $\mathrm{E}^{\prime}$ velocity, even after adjustment for age and systolic blood pressure (Table 3).

In women the association between abdominal adiposity, assessed by waist-to-height ratio, and $\mathrm{E}^{\prime}$ velocity was different according to age ( $\mathrm{p}$ for interaction $=0.01$ ). In women $<65$ years, waist-to-height ratio was associated with decreased $\mathrm{E}^{\prime}$ velocity $(\mathrm{r}=-0.21$; crude $\beta$ : -8.0 , $95 \% \mathrm{CI}:-11.8$ to $-4.3 ; \mathrm{p}<0.01$ ) but, after adjustment for SBP, we observed an attenuation of this association (adjusted $\beta$ : $-2.3 ; 95 \% \mathrm{Cl}$ : -6.1 to $1.6 ; p=0.25$ ). In this subgroup, a similar association was observed between waist-to-height ratio and $\mathrm{E} / \mathrm{E}^{\prime}$ ratio (crude $\beta$ : $4.3,95 \%$ CI: 1.7 to $6.8 ; \mathrm{p}=0.001$ ), which was no longer significant after adjustment for SBP.

\subsection{Adiposity and diastolic dysfunction parameters in men}

In men, BMI was associated with decreased $\mathrm{E}^{\prime}$ velocity $(\mathrm{p}<0.001)$ increased $\mathrm{E} / \mathrm{E}^{\prime}$ ratio $(\mathrm{p}<0.001)$ and a higher likelihood of diastolic dysfunction (adjusted OR: 1.17; 95\% CI: 1.09-1.27; p < 0.001), even after adjustment for age and SBP. We also found an association between fat mass percentage with $\mathrm{E}^{\prime}$ velocity $(\mathrm{p}<0.001)$ and $\mathrm{E} / \mathrm{E}^{\prime}$ ratio $(\mathrm{p}<0.001)$. The association between DD and BMI or fat mass \% was significant in both age groups, but stronger in younger men ( $p$ for interaction of 0.03 and 0.04 , respectively), as shown in Table 3.

In men younger than 65 years, $E^{\prime}$ velocity was more strongly correlated with abdominal obesity, namely with waist-to-height ratio, than with BMI. After adjustment for age and SBP, waist-to-height ratio was associated with decreased $\mathrm{E}^{\prime}$ velocity and increased $\mathrm{E} / \mathrm{E}^{\prime}$ ratio (adjusted $\beta: 9.7,95 \%$ CI: 5.4-10.0; $p<0.001$ ). In men older than 65 years, we also observed an association between waist-to-height ratio and $\mathrm{E}^{\prime}$ velocity, but of lesser magnitude compared to younger patients (Table 3 ).

\subsection{Pathophysiological path analysis for the association between waist-to-height ratio and diastolic function}

Fig. 1 shows schematically the tested model for the path analysis between waist-to-height ratio and $\mathrm{E}^{\prime}$ velocity. Table 4 presents the estimated total, direct and indirect effects of abdominal adiposity (waistto-height ratio) on $\mathrm{E}^{\prime}$ velocity.

In men, the association between waist-to-height ratio and $\mathrm{E}^{\prime}$ velocity was significant in both age groups and mainly determined by a direct effect. As shown in Table 4, in men younger than 65 years, $81.3 \%$ of the 
Table 2

Clinical characteristics according to diastolic dysfunction grades.

\begin{tabular}{|c|c|c|c|c|}
\hline & $\begin{array}{l}\text { Normal diastolic function } \\
\mathrm{n}=792(74.5 \%)\end{array}$ & $\begin{array}{l}\text { Mild diastolic dysfunction } \\
\mathrm{n}=151(14.2 \%)\end{array}$ & $\begin{array}{l}\text { Moderate or severe diastolic dysfunction } \\
\mathrm{n}=95(8.9 \%)\end{array}$ & $\mathrm{p}$ value for trend \\
\hline Age, years & $59.9 \pm 10.0$ & $70.3 \pm 8.7$ & $68.0 \pm 8.7$ & $<0.001$ \\
\hline Female, n (\%) & $482(60.8 \%)$ & $99(65.5 \%)$ & $63(66.3 \%)$ & 0.58 \\
\hline Hypertension, n (\%) & $380(60.6 \%)$ & $265(85.2 \%)$ & $69(95.7 \%)$ & $<0.001$ \\
\hline Systolic blood pressure, $\mathrm{mm} \mathrm{Hg}$ & $131.6 \pm 19.4$ & $147.0 \pm 23.1$ & $141.7 \pm 18.3$ & $<0.001$ \\
\hline Diastolic blood pressure, $\mathrm{mm} \mathrm{Hg}$ & $81.1 \pm 10.5$ & $83.3 \pm 11.4$ & $63.3 \pm 11.1$ & 0.02 \\
\hline Log hsCRP, mg/dL & 0.18 & 0.21 & 0.24 & $<0.001$ \\
\hline \multicolumn{5}{|l|}{ Adiposity parameters } \\
\hline $\mathrm{BMI}, \mathrm{kg} / \mathrm{m}^{2}$ & $27.1 \pm 4.6$ & $28.1 \pm 4.2$ & $28.3 \pm 4.3$ & $<0.001$ \\
\hline Fat mass, $\%$ & $30.6 \pm 8.6$ & $33.4 \pm 7.3$ & $33.9 \pm 7.3$ & $<0.001$ \\
\hline Waist-to-height ratio, $\mathrm{cm} / \mathrm{cm}$ & $0.58 \pm 0.07$ & $0.61 \pm 0.07$ & $0.60 \pm 0.06$ & $<0.001$ \\
\hline Hip-to-height ratio, $\mathrm{cm} / \mathrm{cm}$ & $0.63 \pm 0.07$ & $0.65 \pm 0.06$ & $0.64 \pm 0.06$ & $<0.001$ \\
\hline Waist-to-hip ratio & $0.91 \pm 0.08$ & $0.94 \pm 0.07$ & $0.94 \pm 0.08$ & $<0.001$ \\
\hline \multicolumn{5}{|l|}{ Echocardiography } \\
\hline LA volume index, $\mathrm{mL} / \mathrm{m}^{2}$ & $28.7 \pm 9.5$ & $30.0 \pm 11.7$ & $30.4 \pm 12.3$ & 0.35 \\
\hline LV mass index, $\mathrm{g} / \mathrm{m}^{2}$ & $76.7 \pm 17.0$ & $91.6 \pm 21.8$ & $91.7 \pm 29.9$ & $<0.001$ \\
\hline $\mathrm{E}^{\prime}$ velocity, $\mathrm{cm} / \mathrm{s}$ & $11.7 \pm 2.7$ & $6.4 \pm 1.0$ & $6.6 \pm 1.1$ & $<0.001$ \\
\hline $\mathrm{E} / \mathrm{E}^{\prime}$ ratio & $6.4 \pm 1.7$ & $9.6 \pm 2.5$ & $11.9 \pm 3.4$ & $<0.001$ \\
\hline E/A ratio & $1.0 \pm 0.3$ & $0.6 \pm 0.1$ & $1.0 \pm 0.4$ & $<0.001$ \\
\hline Deceleration time, ms & $230.0 \pm 48.9$ & $286.9 \pm 75.6$ & $234.0 \pm 50.2$ & $<0.001$ \\
\hline IVRT, ms & $90.8 \pm 14.8$ & $101.2 \pm 15.9$ & $90.9 \pm 18.8$ & $<0.001$ \\
\hline
\end{tabular}

Data are presented as mean and standard deviation for continuous variables and count and percentage for categorical variables.

BMI, body mass index; BP, blood pressure; hsCRP, high sensitivity C-reactive protein; IVRT, isovolumetric relaxation time; LA, left atrium; LV, left ventricle.

effect ( $-12.762,95 \% \mathrm{CI}:-19.520$ to -6.005$)$ was direct, $12.4 \%$ was mediated by inflammation $(-1.954 ;-3.902$ to -0.005$)$ and $6.3 \%$ via SBP $(-0.982 ; 95 \% \mathrm{CI}:-3.301$ to 1.336$)$. In men older than 65 years, most of the effect was also direct (92.0\%).

In women, we found an association between abdominal adiposity and $\mathrm{E}^{\prime}$ velocity only in the younger group. Contrary to men, most of the effect of waist-to-height ratio on $\mathrm{E}^{\prime}$ velocity was indirect, mainly through SBP (50.8\%), with non-significant proportions of $15.1 \%$ via inflammation and $34.2 \%$ by direct effect (Table 4 ).

\section{Discussion}

In this population-based study we found that diastolic function is independently associated with several adiposity parameters, especially abdominal adiposity. This association is more important in men and in the younger population. Moreover, in men, abdominal adiposity was related with worse diastolic function mainly by direct (adiposity mediated) mechanisms, while in women the predominant effect was indirect, mainly through hypertension.
4.1. The association between diastolic dysfunction and adiposity distribution parameters

In this study we have shown that increased BMI is independently associated with worse diastolic function, which is in accordance with previous studies showing the same independent association $[13,26]$. We observed that this association is more important in men and in younger people. Considering that subclinical diastolic dysfunction is a predictor of future heart failure risk [27], and BMI is known as an independent risk factor for incident heart failure $[9,28]$, it has been proposed that diastolic dysfunction can be one of the important pathophysiological links between obesity, heart failure and mortality [29]. Besides, some studies have shown that long-term weight loss, for example after bariatric surgery, can improve diastolic function [30,31], an observation that supports this relation. However, it is known that BMI is an imperfect measure of fat mass, as it can be influenced by several other factors [21]. In this study, we have shown the same independent association of diastolic dysfunction with fat mass percentage, evaluated by bioimpedance analysis, which also strengthens the link between total adiposity and worse diastolic function.

Table 3

Univariate and multivariate linear regression analyses for the association between $\mathrm{E}^{\prime}$ velocity and several adiposity parameters according to age and sex.

\begin{tabular}{|c|c|c|c|c|c|c|c|c|c|}
\hline & \multicolumn{4}{|c|}{$<65$ years } & \multicolumn{4}{|c|}{$\geq 65$ years } & \multirow[b]{3}{*}{$\begin{array}{l}\mathrm{p} \text { value for } \\
\text { interaction }\end{array}$} \\
\hline & \multicolumn{2}{|l|}{ Crude } & \multicolumn{2}{|l|}{ Adjusted $^{\mathrm{a}}$} & \multicolumn{2}{|l|}{ Crude } & \multicolumn{2}{|l|}{ Adjusted $^{\mathrm{a}}$} & \\
\hline & $\beta(95 \% \mathrm{CI})$ & $\mathrm{r}$ & $\beta(95 \% \mathrm{CI})$ & $\begin{array}{l}\mathrm{p} \\
\text { value }\end{array}$ & $\beta(95 \% \mathrm{CI})$ & $\mathrm{r}$ & $\beta(95 \% \mathrm{CI})$ & $\begin{array}{l}\mathrm{p} \\
\text { value }\end{array}$ & \\
\hline \multicolumn{10}{|l|}{ Women } \\
\hline BMI, $\mathrm{kg} / \mathrm{m}^{2}$ & $-0.10(-0.15$ to -0.04$)$ & -0.17 & $-0.03(-0.08$ to 0.03$)$ & 0.30 & $0.02(-0.06$ to 0.09$)$ & 0.03 & $0.03(-0.04$ to 0.1$)$ & 0.45 & 0.27 \\
\hline Fat mass, \% & $-0.11(-0.15$ to -0.07$)$ & -0.24 & $-0.04(-0.09$ to -0.01$)$ & 0.04 & $-0.01(-0.06$ to 0.04$)$ & -0.01 & $-0.01(-0.05$ to 0.05$)$ & 0.94 & 0.24 \\
\hline $\begin{array}{l}\text { Waist/height, } \\
\mathrm{cm} / \mathrm{m}\end{array}$ & $-8.0(-11.8$ to -4.3$)$ & -0.21 & $-2.7(-6.4$ to 1.0$)$ & 0.15 & $-2.0(-6.3$ to 2.4$)$ & -0.06 & $0.4(-4.0$ to 4.9$)$ & 0.84 & 0.01 \\
\hline \multicolumn{10}{|l|}{ Men } \\
\hline BMI, $\mathrm{kg} / \mathrm{m}^{2}$ & $-0.30(-0.41$ to -0.18$)$ & -0.33 & $-0.23(-0.34$ to -0.11$)$ & $<0.001$ & $-0.11(-0.22$ to -0.01$)$ & -0.15 & $-0.13(-0.24$ to -0.03$)$ & 0.01 & 0.03 \\
\hline Fat mass, \% & $-0.19(-0.26$ to -0.11$)$ & -0.32 & $-0.14(-0.21$ to -0.06$)$ & $<0.001$ & $-0.06(-0.13$ to 0.01$)$ & -0.12 & $-0.07(-0.13$ to -0.01$)$ & 0.04 & 0.04 \\
\hline $\begin{array}{l}\text { Waist/height, } \\
\mathrm{cm} / \mathrm{m}\end{array}$ & $-19.6(-13.3$ to -25.8$)$ & -0.38 & $-14.4(-21.1$ to -7.6$)$ & $<0.001$ & $-7.9(-14.5$ to -1.2$)$ & -0.17 & $-8.6(-14.9$ to -2.3$)$ & 0.01 & 0.06 \\
\hline
\end{tabular}

$\beta$, regression coefficient; $95 \% \mathrm{CI}$, 95\% confidence interval; BMI, body mass index; r, correlation coefficient.

a Adjusted for age (continuous) and systolic blood pressure (continuous). 
Table 4

Path analysis with estimated total, direct and indirect effects of waist-to-height ratio on $\mathrm{E}^{\prime}$ velocity.

\begin{tabular}{|c|c|c|c|c|}
\hline & \multicolumn{2}{|c|}{ Women } & \multicolumn{2}{|c|}{ Men } \\
\hline & $<65$ years & $\geq 65$ years & $<65$ years & $\geq 65$ years \\
\hline Total & $-4.985(-8.377$ to -1.592$)$ & $-0.253(-4.536$ to 4.030$)$ & $-15.698(-22.051$ to -9.346$)$ & $-9.208(-15.584$ to -2.833$)$ \\
\hline Direct & $-1.703(-5.818$ to 2.412$)$ & $0.652(-3.821$ to 5.125$)$ & $-12.762(-19.520$ to -6.005$)$ & $-8.480(-14.852$ to -2.108$)$ \\
\hline Indirect - role of SBP & $-2.531(-4.189$ to -0.873$)$ & $-0.998(-2.157$ to 0.162$)$ & $-0.982(-3.301$ to 1.336$)$ & $-0.521(-1.522$ to 0.481$)$ \\
\hline Indirect - role of hsCRP & $-0.751(-2.723$ to 1.221$)$ & $0.093(-0.757$ to 0.943$)$ & $-1.954(-3.902$ to -0.005$)$ & $-0.21(-0.839$ to 0.425$)$ \\
\hline CFI & 0.990 & 1.000 & 0.946 & 1.000 \\
\hline
\end{tabular}

Standardized regression coefficients and 95\% confidence intervals (in parentheses) were calculated by bootstrapping using 1000 draws.

$\mathrm{CFI}$, comparative fit index; hsCRP, high sensitivity $\mathrm{C}$ reactive protein; SBP, systolic blood pressure.

Abdominal obesity parameters, especially waist circumference, are more closely related with excess visceral fat, which is the most metabolically active fat [21]. Several studies have shown that compared to BMI, abdominal obesity is a stronger determinant of myocardial infarction, cardiovascular disease and death [32,33]. In our population we observed that increased waist-to height ratio was a stronger determinant of diastolic dysfunction, especially in men. The association between waist-to height ratio and diastolic function was independent of BMI, which emphasizes a specific role for visceral fat. This observation is consistent with recently published data, that have also shown that waist circumference [34], and increased abdominal visceral fat mass assessed by CT scan [35], are independent determinants of diastolic dysfunction, independently of BMI and subcutaneous fat, respectively. The confirmation of abdominal obesity as a more important determinant of subclinical left ventricle diastolic dysfunction might have important clinical implications, particularly by the increasing prevalence of obesity worldwide. Interestingly, previous studies have observed an association between waist circumference and incident heart failure [36], which was independent of BMI [37]. Also, recent prospective studies have confirmed that subclinical diastolic dysfunction is associated with the development of heart failure, especially with heart failure with preserved ejection fraction (HFpEF) [27,38]. Therefore, the early identification and correction of the main determinants of subclinical diastolic dysfunction, such as abdominal obesity, can be particularly important in the prevention of HFpEF, a disease where no therapy has been shown to change the prognosis. This will need to be confirmed in future longitudinal studies.

4.2. The role of sex in the association between adiposity and diastolic dysfunction

The total amount of fat and its distribution is quite different in men and women. It is known that younger women have a more peripheral and subcutaneous distribution of fat but, later, menopause induces a more abdominal distribution of fat with increasing age. Therefore, we hypothesized that the effect on left ventricle diastolic function could be sex- and age-specific. In this study we observed a stronger relation between adiposity parameters and diastolic dysfunction in men than in women, and this difference is especially apparent in the younger population. Most of the previous studies that have also evaluated the relation between obesity and diastolic function did not assess the sex difference [29] or did not find a significant difference in effect [13]. However, Canepa et al., found that the association between waist circumference and diastolic function was more pronounced in women than in men [34]. Nevertheless, these results could be partially explained by women being significantly younger than men, bearing in mind that in our study the association between adiposity and diastolic function is also age dependent. Also, body composition differs significantly between racial and ethnical subgroups and our study was conducted in a European population, while the study from Canepa et al. included $29 \%$ of African origin participants.

\subsection{Direct and indirect mechanisms linking adiposity and diastolic dysfunction}

The pathophysiological pathways that link obesity with diastolic dysfunction are not entirely understood. This association can be mediated by a combination of both direct and indirect effects that, according to our results, seem to be sex specific. The effect can be indirect, through established risk factors that can also induce diastolic dysfunction. Alternatively, this effect can be caused by the secretion of adipokines that have been shown to modulate myocardial structure and function by inducing a systemic pro-inflammatory effect and/or by causing direct hemodynamic and mechanical changes in the heart and cardiovascular system [28].

In our study, we have shown that the association between the several adiposity parameters and DD is partially attenuated when adjusting for age and mainly for blood pressure, which is consistent with previous studies [13]. As shown in the path analysis, this indirect effect through systolic blood pressure is especially important in younger women, being responsible for about $50 \%$ of the effect. Interestingly, another study including only patients with hypertension found that the adverse effect of abdominal obesity on left ventricle diastolic function was more pronounced among hypertensive females [39].

Adipose tissue is an important source of proinflammatory cytokines [17]. Previous studies have linked inflammation with diastolic dysfunction in patients with hypertension [40] and coronary artery disease [41] and, in experimental studies, the inhibition of inflammatory pathways prevented diastolic dysfunction development [42]. Therefore, the role of adiposity on diastolic dysfunction can be at least partially mediated by inflammation. The path analysis that we have performed showed that in individuals younger than 65 years, the effect of waist-to-height ratio on diastolic dysfunction was mediated by hsCRP, which was responsible for $12.4 \%$ and $15.1 \%$ of this indirect effect in men and women, respectively. Interestingly, systemic inflammatory state has been shown to be predictive of incident HF, especially of HFpEF [43] and, more importantly, previous studies have proposed that the association between obesity and HF may be related to pathophysiologic pathways associated with inflammation [44]. Combining all these observations, Paulus and Tschope [45] have recently proposed a novel paradigm for HFpEF development which identifies a systemic proinflammatory state, induced by obesity and other comorbidities, as a cause of reduced nitric oxide availability and decreased protein kinase $\mathrm{G}$ activity inducing stiffer cardiomyocytes and interstitial fibrosis deposition.

Finally, obesity can directly influence myocardial structure and function through other mechanisms, some not evaluated in this study. As observed in the path analysis performed, in men younger than 65 years, the direct effect can be responsible for up to $80 \%$ of the association between abdominal obesity and diastolic dysfunction. Several other pathophysiological mechanisms can be involved. Adipose tissue is an endocrine organ capable of secreting several adipokines (such as leptin, adiponectin, resistin and others) that have been shown to induce left 
ventricle remodeling and myocardial dysfunction [46]. Indeed, it has been suggested that the association between obesity and HF may be partially mediated by plasma leptin [28]. Also, obese patients have increased myocardial fatty infiltration that can lead to the worse diastolic dysfunction [47]. Furthermore, the excess in body fat determines an increase in both preload and afterload, due to a hyperdynamic circulation, chronic volume overload, and increase in peripheral resistance [48], which have also been shown to influence diastolic function [49].

\subsection{Strengths and limitations}

To assess the pathophysiological mechanisms involved in the now well-established association between increased adiposity and diastolic dysfunction we used a path analysis, which is an extension of regression analysis, being increasingly used to decompose and compare the magnitudes of effects between variables with complex interrelations or to test the plausibility of mediation effects. Other strengths of this study include the large sample of individuals free from other cardiac diseases, the contemporaneous assessment of cardiac diastolic function using the most recent consensus criteria for diastolic function evaluation and the use of several adiposity parameters including anthropometry and bioimpedance analysis to measure fat mass distribution.

The main limitation of this study is the cross-sectional design, which partially limits comments on causality, as this would be more robust in a prospective design. Although we have excluded patients with clinical signs of coronary artery disease, we did not perform any stress test to exclude myocardial ischemia, which is one determinant of diastolic dysfunction. We did not evaluate the intraobserver and interobserver variability in the evaluation of diastolic function. However, all the cardiologists had extensive experience in echocardiography, worked in the same institution and a detailed procedure protocol was discussed between the team, prior to study beginning in order to harmonize the methodology and the measurements. Moreover, several previous studies have shown a good reproducibility and a low inter-observer mean error for diastolic parameters [50].

\section{Conclusion}

Obesity, especially abdominal obesity, was associated with worse diastolic function. This association was stronger in men than in women and in the younger population. The causal mechanisms potentially involved were sex-specific, being mainly mediated by blood pressure in women, while in men there was mainly a direct effect.

\section{Conflict of interest}

None of the authors have conflicts of interest to declare.

\section{Acknowledgments}

This work was supported by Portuguese Foundation for Science and Technology Grants POCI/SAU-ESP/61492/2004, PEST-C/SAU/UI0051/ 2011, and EXCL/BIM-MEC/0055/2012 (partially funded by FEDER through COMPETE) and European Commission Grant FP7-Health2010; MEDIA-261409.

Alexandra Gonçalves receives funds from Portuguese Foundation for Science and Technology Grant HMSP-ICS/007/2012.

\section{References}

[1] J.N. Cohn, R. Ferrari, N. Sharpe, Cardiac remodeling-concepts and clinical implications: a consensus paper from an international forum on cardiac remodeling. Behalf of an International Forum on Cardiac Remodeling, J. Am. Coll. Cardiol. 35 (2000) 569-582.

[2] C.W. Yancy, M. Jessup, B. Bozkurt, J. Butler, D.E. Casey Jr., M.H. Drazner, et al., ACCF/ AHA Guideline for the Management of Heart Failure: Executive Summary: a Report of the American College of Cardiology Foundation/American Heart Association Task Force on Practice Guidelines, Circulation 2013 (2013).

[3] J.J. McMurray, S. Adamopoulos, S.D. Anker, A. Auricchio, M. Bohm, K. Dickstein, et al., ESC Guidelines for the diagnosis and treatment of acute and chronic heart failure 2012: the Task Force for the Diagnosis and Treatment of Acute and Chronic Heart Failure 2012 of the European Society of Cardiology. Developed in collaboration with the Heart Failure Association (HFA) of the ESC, Eur. Heart J. 33 (2012) 1787-1847.

[4] T.E. Owan, D.O. Hodge, R.M. Herges, S.J. Jacobsen, V.L. Roger, M.M. Redfield, Trends in prevalence and outcome of heart failure with preserved ejection fraction, $\mathrm{N}$. Engl. J. Med. 355 (2006) 251-259.

[5] R.S. Bhatia, J.V. Tu, D.S. Lee, P.C. Austin, J. Fang, A. Haouzi, et al., Outcome of heart failure with preserved ejection fraction in a population-based study, N. Engl. J. Med. 355 (2006) 260-269.

[6] A.F. Leite-Moreira, Current perspectives in diastolic dysfunction and diastolic heart failure, Heart 92 (2006) 712-718.

[7] M.R. Zile, J.S. Gottdiener, S.J. Hetzel, J.J. McMurray, M. Komajda, R. McKelvie, et al., Prevalence and significance of alterations in cardiac structure and function in patients with heart failure and a preserved ejection fraction, Circulation 124 (2011) 2491-2501

[8] W.J. Paulus, C. Tschope, J.E. Sanderson, C. Rusconi, F.A. Flachskampf, F.E. Rademakers, et al., How to diagnose diastolic heart failure: a consensus statement on the diagnosis of heart failure with normal left ventricular ejection fraction by the Heart Failure and Echocardiography Associations of the European Society of Cardiology, Eur. Heart J. 28 (2007) 2539-2550.

[9] S. Kenchaiah, J.C. Evans, D. Levy, P.W. Wilson, E.J. Benjamin, M.G. Larson, et al., Obesity and the risk of heart failure, N. Engl. J. Med. 347 (2002) 305-313.

[10] C.J. Lavie, M.A. Alpert, R. Arena, M.R. Mehra, R.V. Milani, H.O. Ventura, Impact of obesity and the obesity paradox on prevalence and prognosis in heart failure, JACC Heart Fail. 1 (2013) 93-102.

[11] M.A. Alpert, J. Omran, A. Mehra, S. Ardhanari, Impact of obesity and weight loss on cardiac performance and morphology in adults, Prog. Cardiovasc. Dis. 56 (2014) 391-400.

[12] M. Bastien, P. Poirier, I. Lemieux, J.P. Despres, Overview of epidemiology and contribution of obesity to cardiovascular disease, Prog. Cardiovasc. Dis. 56 (2014) 369-381.

[13] C. Russo, Z. Jin, S. Homma, T. Rundek, M.S. Elkind, R.L. Sacco, et al., Effect of obesity and overweight on left ventricular diastolic function: a community-based study in an elderly cohort, J. Am. Coll. Cardiol. 57 (2011) 1368-1374.

[14] T.B. Horwich, G.C. Fonarow, Glucose, obesity, metabolic syndrome, and diabetes relevance to incidence of heart failure, J. Am. Coll. Cardiol. 55 (2010) 283-293.

[15] S.S. Martin, A. Qasim, M.P. Reilly, Leptin resistance: a possible interface of inflammation and metabolism in obesity-related cardiovascular disease, J. Am. Coll. Cardiol. 52 (2008) 1201-1210.

[16] S.B. Patel, G.P. Reams, R.M. Spear, R.H. Freeman, D. Villarreal, Leptin: linking obesity, the metabolic syndrome, and cardiovascular disease, Curr. Hypertens. Rep. 10 (2008) 131-137.

[17] A. Taube, R. Schlich, H. Sell, K. Eckardt, J. Eckel, Inflammation and metabolic dysfunction: links to cardiovascular diseases, Am. J. Physiol. Heart Circ. Physiol. 302 (2012) H2148-H2165.

[18] J.P. Bastard, C. Jardel, J. Delattre, B. Hainque, E. Bruckert, F. Oberlin, Evidence for a link between adipose tissue interleukin-6 content and serum C-reactive protein concentrations in obese subjects, Circulation 99 (1999) 2221-2222.

[19] B.D. Powell, M.M. Redfield, K.A. Bybee, W.K. Freeman, C.S. Rihal, Association of obesity with left ventricular remodeling and diastolic dysfunction in patients without coronary artery disease, Am. J. Cardiol. 98 (2006) 116-120.

[20] C.Y. Wong, T. O'Moore-Sullivan, R. Leano, N. Byrne, E. Beller, T.H. Marwick, Alterations of left ventricular myocardial characteristics associated with obesity, Circulation 110 (2004) 3081-3087.

[21] M.A. Cornier, J.P. Despres, N. Davis, D.A. Grossniklaus, S. Klein, B. Lamarche, et al., Assessing adiposity: a scientific statement from the American Heart Association, Circulation 124 (2011) 1996-2019.

[22] E. Ramos, C. Lopes, H. Barros, Investigating the effect of nonparticipation using a population-based case-control study on myocardial infarction, Ann. Epidemiol. 14 (2004) 437-441.

[23] R.M. Lang, M. Bierig, R.B. Devereux, F.A. Flachskampf, E. Foster, P.A. Pellikka, et al., Recommendations for chamber quantification, Eur. J. Echocardiogr. 7 (2006) 79-108.

[24] S.F. Nagueh, C.P. Appleton, T.C. Gillebert, P.N. Marino, J.K. Oh, O.A. Smiseth, et al., Recommendations for the evaluation of left ventricular diastolic function by echocardiography, Eur. J. Echocardiogr. 10 (2009) 165-193.

[25] JC L, Latent Variable Models: An Introduction to Factor, Path, and Structural Equation Analysis, Psychology Press, Hove, United Kingdom, 2003.

[26] W. Aljaroudi, C. Halley, P. Houghtaling, S. Agarwal, V. Menon, L. Rodriguez, et al., Impact of body mass index on diastolic function in patients with normal left ventricular ejection fraction, Nutr. Diabetes 2 (2012) e39.

[27] G.C. Kane, B.L. Karon, D.W. Mahoney, M.M. Redfield, V.L. Roger, J.C. Burnett Jr., et al., Progression of left ventricular diastolic dysfunction and risk of heart failure, JAMA 306 (2011) 856-863.

[28] S.G. Wannamethee, A.G. Shaper, P.H. Whincup, L. Lennon, N. Sattar, Obesity and risk of incident heart failure in older men with and without pre-existing coronary heart disease: does leptin have a role? J. Am. Coll. Cardiol. 58 (2011) 1870-1877.

[29] K.A. Ammar, M.M. Redfield, D.W. Mahoney, M. Johnson, S.J. Jacobsen, R.J. Rodeheffer, Central obesity: association with left ventricular dysfunction and mortality in the community, Am. Heart J. 156 (2008) 975-981. 
[30] H.J. Willens, S.C. Chakko, P. Byers, J.A. Chirinos, E. Labrador, J.C. Castrillon, et al., Effects of weight loss after gastric bypass on right and left ventricular function assessed by tissue Doppler imaging, Am. J. Cardiol. 95 (2005) 1521-1524.

[31] O.J. Rider, J.M. Francis, M.K. Ali, S.E. Petersen, M. Robinson, M.D. Robson, et al., Beneficial cardiovascular effects of bariatric surgical and dietary weight loss in obesity, J. Am. Coll. Cardiol. 54 (2009) 718-726.

[32] R. Huxley, S. Mendis, E. Zheleznyakov, S. Reddy, J. Chan, Body mass index, waist circumference and waist:hip ratio as predictors of cardiovascular risk-a review of the literature, Eur. J. Clin. Nutr. 64 (2010) 16-22.

[33] T. Pischon, H. Boeing, K. Hoffmann, M. Bergmann, M.B. Schulze, K. Overvad, et al., General and abdominal adiposity and risk of death in Europe, N. Engl. J. Med. 359 (2008) 2105-2120.

[34] M. Canepa, J.B. Strait, D. Abramov, Y. Milaneschi, M. AlGhatrif, M. Moni, et al., Contribution of central adiposity to left ventricular diastolic function (from the Baltimore Longitudinal Study of Aging), Am. J. Cardiol. 109 (2012) 1171-1178.

[35] M. Canepa, J.B. Strait, Y. Milaneschi, M. Alghatrif, R. Ramachandran, S. Makrogiannis, et al., The relationship between visceral adiposity and left ventricular diastolic function: results from the Baltimore Longitudinal Study of Aging, Nutr. Metab. Cardiovasc. Dis. 23 (2013) 1263-1270.

[36] G. Hu, P. Jousilahti, R. Antikainen, P.T. Katzmarzyk, J. Tuomilehto, Joint effects of physical activity, body mass index, waist circumference, and waist-to-hip ratio on the risk of heart failure, Circulation 121 (2010) 237-244

[37] B.J. Nicklas, M. Cesari, B.W. Penninx, S.B. Kritchevsky, J. Ding, A. Newman, et al., Abdominal obesity is an independent risk factor for chronic heart failure in older people, J. Am. Geriatr. Soc. 54 (2006) 413-420.

[38] C.S. Lam, A. Lyass, E. Kraigher-Krainer, J.M. Massaro, D.S. Lee, J.E. Ho, et al., Cardiac dysfunction and noncardiac dysfunction as precursors of heart failure with reduced and preserved ejection fraction in the community, Circulation 124 (2011) 24-30.

[39] C.P. Tsioufis, D.L. Tsiachris, M.N. Selima, K.S. Dimitriadis, C.G. Thomopoulos, D.C. Tsiliggiris, et al., Impact of waist circumference on cardiac phenotype in hypertensives according to gender, Obesity 17 (2009) 177-182.

[40] S. Sciarretta, A. Ferrucci, G.M. Ciavarella, P. De Paolis, V. Venturelli, G. Tocci, et al., Markers of inflammation and fibrosis are related to cardiovascular damage in hypertensive patients with metabolic syndrome, Am. J. Hypertens. 20 (2007) 784-791.

[41] E.S. Williams, S.J. Shah, S. Ali, B.Y. Na, N.B. Schiller, M.A. Whooley, C-reactive protein, diastolic dysfunction, and risk of heart failure in patients with coronary disease: Heart and Soul Study, Eur. J. Heart Fail. 10 (2008) 63-69.
[42] D. Westermann, S. Van Linthout, S. Dhayat, N. Dhayat, A. Schmidt, M. Noutsias, et al., Tumor necrosis factor-alpha antagonism protects from myocardial inflammation and fibrosis in experimental diabetic cardiomyopathy, Basic Res. Cardiol. 102 (2007) 500-507.

[43] A. Kalogeropoulos, V. Georgiopoulou, B.M. Psaty, N. Rodondi, A.L. Smith, D.G Harrison, et al., Inflammatory markers and incident heart failure risk in older adults: the Health ABC (Health, Aging, and Body Composition) study, J. Am. Coll. Cardiol. 55 (2010) 2129-2137.

[44] H. Bahrami, D.A. Bluemke, R. Kronmal, A.G. Bertoni, D.M. Lloyd-Jones, E. Shahar et al., Novel metabolic risk factors for incident heart failure and their relationship with obesity: the MESA (Multi-Ethnic Study of Atherosclerosis) study, J. Am. Coll. Cardiol. 51 (2008) 1775-1783.

[45] W.J. Paulus, C. Tschope, A novel paradigm for heart failure with preserved ejection fraction: comorbidities drive myocardial dysfunction and remodeling through coronary microvascular endothelial inflammation, J. Am. Coll. Cardiol. 62 (2013) 263-271.

[46] I. Falcao-Pires, P. Castro-Chaves, D. Miranda-Silva, A.P. Lourenco, A.F. Leite-Moreira, Physiological, pathological and potential therapeutic roles of adipokines, Drug Discov. Today 17 (2012) 880-889.

[47] R.W. van der Meer, L.J. Rijzewijk, M. Diamant, S. Hammer, M. Schar, J.J. Bax, et al. The ageing male heart: myocardial triglyceride content as independent predictor of diastolic function, Eur. Heart J. 29 (2008) 1516-1522.

[48] V. Palmieri, G. de Simone, D.K. Arnett, J.N. Bella, D.W. Kitzman, A. Oberman, et al., Relation of various degrees of body mass index in patients with systemic hypertension to left ventricular mass, cardiac output, and peripheral resistance (The Hypertension Genetic Epidemiology Network Study), Am. J. Cardiol. 88 (2001) 1163-1168.

[49] A.F. Leite-Moreira, A.P. Lourenco, R. Roncon-Albuquerque Jr., T. Henriques-Coelho, M.J. Amorim, J. Almeida, et al., Diastolic tolerance to systolic pressures closely reflects systolic performance in patients with coronary heart disease, Basic Res. Cardiol. 107 (2012) 251.

[50] H. Dalen, A. Thorstensen, L.J. Vatten, S.A. Aase, A. Stoylen, Reference values and distribution of conventional echocardiographic Doppler measures and longitudina tissue Doppler velocities in a population free from cardiovascular disease, Circ. Cardiovasc. Imaging 3 (2010) 614-622. 